\title{
Avaliação dos testes rápidos para diagnóstico da dengue no Brasil
}

\section{Evaluation of rapid diagnostic tests for dengue in Brazil}

\author{
Helena Cristina Balthazar \\ Guedes Borges',* (iD \\ Marisa Coelho Adati' \\ Danielle Copello Vigo' iD \\ Valeria Furtado de Mendonça' iD \\ Marlon Akio Issobel iD \\ Flavia Barreto dos Santos"
}

Helena Pereira da Silva Zamith"II iD

\begin{abstract}
RESUMO
Introdução: 0 aumento do número de casos de dengue no mundo estimulou o desenvolvimento e a disponibilização no mercado nacional e internacional de testes de execução rápida e simples para o diagnóstico da doença. Objetivo: Avaliar a sensibilidade e especificidade diagnóstica de Testes Rápidos (TR) imunocromatográficos para detecção de antígeno (Ag) NS1 e de anticorpos (Ac) das classes G (IgG) e M (IgM) e detecção combinada de Ag e Ac (NS1/ IgG/IgM) do vírus da dengue (DENV), encaminhados para análise prévia no INCQS/Fiocruz, no período de maio de 2016 a dezembro de 2018 para obtenção de registro junto à Anvisa do Brasil. Método: A sensibilidade e a especificidade foram avaliadas frente a painéis de amostras verdadeiramente positivas e verdadeiramente negativas para Ag NS1, Ac lgM e lgG do DENV, painéis de desempenho e padrão internacional do National Institute for Biological Standards and Control/Organização Mundial da Saúde (NIBSC/OMS). Os TR que apresentaram valores de sensibilidade e especificidade superiores ou iguais aos declarados pelos fabricantes foram considerados satisfatórios e os com valores inferiores, insatisfatórios. Resultados: Do total de 32 TR avaliados, 23 (71,9\%) foram satisfatórios para sensibilidade e especificidade, destes, nove (39,1\%), para NS1, $11(47,8 \%)$ para lgG/lgM e três $(13,0 \%)$, para os testes combinados NS1/lgG/lgM. Dos nove TR insatisfatórios, quatro $(44,4 \%)$ foram para detecção de NS1; dois $(22,2 \%)$, para lgG/lgM e três $(33,3 \%)$, para NS1/lgG/lgM. Os TR considerados insatisfatórios não foram registrados no Brasil. Conclusões: A análise prévia como prevista na legislação brasileira é de grande importância para a manutenção da qualidade dos TR ofertados ao mercado nacional.
\end{abstract}

PALAVRAS-CHAVE: Controle de Qualidade; Testes Rápidos; Diagnóstico; Dengue

\section{ABSTRACT}

Introduction: The increasing number of dengue cases worldwide has stimulated the interest to develop products for the diagnosis of this disease in national and international markets. Objective: To evaluate the sensitivity and diagnostic specificity of immunochromatographic Rapid Tests (RT) for the detection of NS1 antigen (Ag), antibodies (Ab) IgG and IgM of dengue virus (DENV), and for the detection of combined AgNS1/AblgG/IgM received from May 2016 to December 2018 at the National Institute for Quality Control in Health from Oswaldo Cruz Foundation for previous analysis and registration by the National Health Surveillance Agency (Anvisa) from Brazil. Method: The evaluation was performed using true positive and true negative samples for Ag NS1, Ab IgM and IgG to DENV, commercial performance panels and international standard of the National Institute for Biological Standards and Control/ World Health Organization (NIBSC/WHO). RT that presented sensitivity and/or specificity values higher than or equal to those stated by the manufacturers were considered satisfactory and those with lower values were unsatisfactory. Results: A total of 32 RT were evaluated, $23(71.9 \%)$ were satisfactory for sensitivity and specificity, 9 (39.1\%) for NS1, 11 (47.8\%) for $\operatorname{lgG} / \operatorname{lgM}$ and 3 (13.0\%) for the combined detection NS1/lgG/lgM. From 9 RT considered unsatisfactory, 4 (44.4\%) were for the detection of NS1; 2 (22.2\%) for $\operatorname{lgG} / \operatorname{lgM}$ and 3 (33.3\%) for NS1/lgG/lgM. Unsatisfactory RT were not registered by Anvisa in Brazil. Conclusions: The previous analysis as foreseen in Brazilian regulation is important for the maintenance of RT quality offered to the national market.

KEYWORDS: Quality Control; Rapid Tests; Diagnostic; Dengue
Recebido: 08 jan 2020

Aprovado: 26 ago 2020 


\section{INTRODUÇÃO}

A dengue é uma grande preocupação em termos de saúde pública em todas as regiões tropicais e subtropicais do mundo. A doença é endêmica em mais de 125 países e se expandiu globalmente impulsionada pelas mudanças climáticas, pelo aumento da circulação de pessoas e da urbanização, somadas à insuficiência de programas de controle de vetores ${ }^{1,2,3}$.

No Brasil, segundo dados do Ministério da Saúde, foram registrados, no período de 29/12/2019 a 27/06/2020, 873.093 casos prováveis da doença cuja transmissão se dá através da picada do mosquito do gênero Aedes infectado ${ }^{4}$. Aedes aegypti é o principal vetor, com distribuição ampla em regiões intertropicais no mundo e no Brasil ${ }^{5,6}$. Outras formas de transmissão da doença foram descritas e incluem o transplante de tecidos e órgãos, a transfusão sanguínea e o leite materno $0^{7,8}$. 0 vírus da dengue (DENV) pertence ao gênero Flavivírus e à família Flaviviridae e possui quatro sorotipos distintos (DENV-1, DENV-2, DENV-3 e DENV-4) que podem circular concomitantemente nas regiões onde a doença é hiperendêmica ${ }^{9}$. A infecção em humanos por um sorotipo confere imunidade permanente contra reinfecções subsequentes pelo mesmo sorotipo, mas apenas proteção parcial e temporária contra os outros sorotipos ${ }^{10,11}$.

A doença possui espectro que varia desde a forma assintomática até a ocorrência de quadros graves de hemorragia e choque, podendo evoluir para o óbito. 0 tratamento é baseado principalmente na sintomatologia, por não existir medicamento antiviral específico, e se limita, portanto, ao uso de analgésicos e/ou reposição de líquidos ${ }^{12,13}$.

O diagnóstico, quando baseado exclusivamente em sintomas clínicos, pode ser comprometido pela presença das infecções subclínicas ou assintomáticas, que variam de 0,7\% a 87\% dependendo da população estudada ${ }^{14,15,16}$. Além disso, a dengue pode ser confundida com outras doenças, tanto na fase febril quanto na fase crítica, dentre elas, as doenças febris acompanhadas ou não de exantema, como as causadas pelo vírus Epstein-Barr, vírus do herpes tipo 6, parvovírus B19, rubéola, sarampo e infecções bacterianas ${ }^{17}$ ou pelas doenças de sazonalidade semelhante à dengue, como a leptospirose ${ }^{18}$. Há descrição de reações filogenéticas cruzadas nos testes sorológicos, especialmente em áreas endêmicas onde pode ser confundida com a malária, febre amarela, mayaro, febre de Oropouche, zika e chikungunya ${ }^{19,20,21}$.

O diagnóstico da infecção pelo DENV envolve uma ou mais metodologias que podem incluir o isolamento viral, testes moleculares e sorológicos. Estas permitem a detecção do vírus, do RNA viral, do antígeno (Ag) viral NS1 e de anticorpos (Ac) ao DENV, imunoglobulinas (Ig) das classes $\mathrm{G}$ (IgG) e M (IgM), cada qual com aplicabilidade associada às diferentes fases da doença ${ }^{22,23}$.

Atualmente, testes para detecção do Ag NS1 são amplamente utilizados na fase inicial da doença, que ocorre antes do surgimento de Ac específicos. A proteína NS1 está presente no soro de indivíduos infectados desde o primeiro dia do aparecimento dos sintomas e permanece detectável até o quinto ou sexto dia de evolução da infecção $24,25,26$.

Uma pequena porcentagem dos indivíduos apresenta níveis detectáveis de IgM já no primeiro dia da doença (8\%), que aumentam rapidamente, atingindo seu pico por volta de duas semanas, permanecendo detectáveis por dois a três meses, o que faz desses Ac indicadores de infecção recente. Na resposta secundária, os níveis de IgM são consideravelmente mais baixos do que na resposta primária ${ }^{27}$.

Na infecção primária, Ac lgG começam a aparecer alguns dias após os Ac IgM, sendo detectáveis a partir do quinto dia de infecção. Os títulos de lgG aumentam lentamente a partir da primeira semana de infecção e permanecem detectáveis por toda a vida. Indivíduos com imunidade prévia ao DENV ou mesmo a outro Flavivírus desenvolvem uma resposta secundária caracterizada pelo rápido aumento no título de IgG quase que imediatamente após o início dos sintomas ${ }^{19,28}$.

A detecção de Ac IgA presentes na saliva de indivíduos com infecção pelo DENV já foi avaliada, entretanto não são marcadores frequentemente utilizados no diagnóstico da doença. Os testes de diagnóstico combinados que detectam Ag e Ac, (NS1/lgG/lgM e IgA) facilitam o diagnóstico de indivíduos com infecção pelo DENV em qualquer período do curso clínico da doença ${ }^{28,29}$.

Com o crescimento da demanda por testes mais sensíveis e específicos para detecção precoce, para o diagnóstico e para o acompanhamento do estado clínico da dengue, foi disponibilizada no mercado nacional e internacional uma grande variedade de testes para diagnóstico de uso in vitro (kits de diagnóstico) ${ }^{30,23}$. Dentre os métodos diagnósticos oferecidos, a utilização dos ensaios imunocromatográficos de fluxo lateral conhecidos como testes rápidos (TR) merece destaque ${ }^{31}$. São testes amplamente empregados na detecção do Ag NS1 e de Ac IgM e lgG em muitos serviços públicos e privados de saúde. Caracterizam-se por serem de simples execução e necessitam, na grande maioria, de 15 a 20 min para obtenção do resultado. Possuem baixo custo comparativo quando utilizados em populações numerosas, além de serem convenientes para distribuição nos locais mais distantes dos principais centros de saúde. Entretanto, a sensibilidade e a especificidade dos TR podem variar consideravelmente e dependem do estágio e do tipo de infecção (primária ou secundária) e do sorotipo infectante ${ }^{32,33}$.

Avaliações de desempenho desses produtos têm demonstrado valores de sensibilidade e especificidade discordantes dos declarados pelos fabricantes ${ }^{5,34}$, que, em alguns casos, são realizadas frente a padrões de referência inapropriados ou quantitativo de amostras reduzido ${ }^{36,36}$. Tal fato implica a possibilidade da ocorrência de resultados falso-negativos (FN). Em amostras de indivíduos assintomáticos ou acometidos com a forma mais severa da doença, resultados FN podem acarretar a ausência de tratamento adequado e risco à saúde. Por outro lado, resultados falso-positivos (FP) implicam no tratamento incorreto, 
possivelmente devido à infecção por outro Flavivírus ${ }^{37}$. Testes diagnósticos sensíveis e específicos são necessários para que os indivíduos infectados recebam cuidados apropriados e para que dados epidemiológicos sejam fidedignos na implementação eficiente de políticas públicas de saúde ${ }^{38}$.

\section{Registro de kits de diagnóstico no Brasil}

O registro de kits de diagnóstico no Brasil junto ao Ministério da Saúde é um ato legal que reconhece a adequação de um produto à legislação sanitária. 0 comércio desses produtos está condicionado ao registro na Agência Nacional de Vigilância Sanitária (Anvisa), sendo regulamentado pela Lei $\mathrm{n}^{\circ} 5.991$, de 17 de dezembro de $1973^{39}$, e seu Decreto $n^{\circ} 74.170$, de 10 de junho de $1974^{40}$. Atualmente, está em vigência, a Resolução da Diretoria Colegiada (RDC) $n^{\circ} 36$, de 26 de agosto de $2015^{41}$, que estabelece a classificação de risco, os regimes de controle de cadastro e registro, além dos requisitos de rotulagem e instruções de uso de kits de diagnóstico produzidos no país e dos importados. Os kits de diagnóstico pertencentes à classe de risco I (baixo risco ao indivíduo e à saúde pública) são sujeitos à notificação e classe II (médio risco ao indivíduo e baixo risco à saúde pública) a cadastro. Estão sujeitos a registro junto à Anvisa, os kits de diagnóstico da dengue (classe III) e os de detecção de patologias transmitidas pelo sangue transfundido (doenças sexualmente transmissíveis pelo vírus da imunodeficiência humana (HIV) e pelo vírus linfotrópico de células T humanas (HTLV), doença de Chagas, sífilis e hepatites $\mathrm{B}$ e $\mathrm{C}$ pertencentes à classe IV de risco ${ }^{41,42}$.

Na concessão do registro são avaliadas as informações relativas à fabricação, à composição, ao desempenho, à funcionalidade, à sensibilidade e à especificidade clínica ou diagnóstica, além da adequação aos requisitos regulamentares da RDC n³6/2015, visando minimizar eventuais riscos associados aos produtos ${ }^{41}$.

Neste contexto, o Instituto Nacional de Controle de Qualidade em Saúde (INCQS), pertencente à Fundação Oswaldo Cruz (Fiocruz) e tecnicamente subordinado à Anvisa, atua como referência para as questões científicas e tecnológicas relativas ao controle da qualidade de produtos, ambientes e serviços vinculados à vigilância sanitária (Visa). O INCQS avalia rotineiramente os kits de diagnóstico pertencentes à classe de risco IV empregados na detecção das patologias transmitidas pelo sangue transfundido, nas diferentes metodologias disponíveis, com vistas ao registro na Anvisa como previsto na RDC $n^{\circ} 36 / 2015^{41}$.

A partir de maio de 2016, como parte do processo de obtenção ou revalidação do registro, os produtos destinados ao diagnóstico da dengue passaram a ser submetidos à análise prévia pelo INCQS, conforme disposto no inciso IV do Art. 16 da Lei n ${ }^{\circ} 6.360$, de 23 de setembro de $1976^{43}$, e no item VII do Art. 19 da RDC $n^{\circ} 36 / 2015^{41}$. O deferimento da petição de registro depende do laudo de análise satisfatório do INCQS e ao cumprimento dos requisitos determinados na legislação vigente.

O objetivo deste trabalho foi avaliar a sensibilidade e especificidade clínica ou diagnóstica dos TR imunocromatográficos empregados no diagnóstico sorológico da dengue, como parte do processo de obtenção do registro junto à Anvisa. Os resultados obtidos foram comparados aos declarados nas instruções de uso dos produtos pelos fabricantes.

\section{MÉTODO}

Em cumprimento à exigência para realização de análise prévia de produtos emitida pela Anvisa, no período de maio de 2016 a dezembro de 2018 foram encaminhadas ao INCQS pelos respectivos solicitantes (fabricantes, importadores/distribuidores), 500 unidades de cada produto (TR) acompanhadas do dossiê de produção e do controle da qualidade, além do certificado de liberação do lote. Trinta e dois TR de diferentes fabricantes foram avaliados totalizando a execução de 16.000 análises. De forma a eliminar os riscos à garantia da confidencialidade das informações e resultados e à imparcialidade dos processos que culminam nas conclusões institucionais, todas as informações referentes aos TR como nome comercial, fabricante, distribuidor/importador, procedência, bem como os valores individuais de sensibilidade e especificidade diagnóstica constantes nas embalagens e instruções de uso dos produtos, foram omitidas.

\section{Painéis sorológicos}

A sensibilidade dos TR foi avaliada frente a painéis sorológicos constituídos por amostras clínicas de soro/plasma verdadeiramente positivas (VP) para Ag NS1 $(n=100)$, para Ac IgM $(n=100)$ e para Ac lgG $(n=100)$. As amostras foram obtidas durante surtos epidêmicos da dengue no estado do Rio de Janeiro no período de março de 2010 a maio de 2013 e caracterizadas por duas ou mais metodologias. Na detecção de Ag NS1, de Ac IgM e lgG foi empregado o ensaio imunoenzimático (ELISA) e TR. A reação em cadeia da polimerase via transcriptase reversa (RT-PCR) foi empregada na determinação do sorotipo das amostras que apresentaram carga viral detectável. A especificidade foi determinada frente a um painel sorológico constituído de 200 amostras de soro/plasma verdadeiramente negativas (VN) coletadas em regiões não endêmicas de dengue (estados da região sul do país), no período de 2013 a 2014, caracterizadas por duas ou mais metodologias (ELISA, TR e RT-PCR). Além disso, foram incluídos na avaliação, painéis sorológicos de desempenho (PVD 201-Anti-Dengue Mixed Titer Performance Panel $(\mathrm{n}=21$ ) e 0845-0051 Anti-Dengue Mixed Titer Accuset Performance Panel Modified $(n=16)$, Sera Care Life Science ${ }^{\oplus}$ ) e o padrão internacional da Organização Mundial da Saúde (OMS), Anti-Dengue Virus Types 1+2+3+4 (Reference Reagent 02/186) $)^{44}$.

\section{Avaliação da sensibilidade e especificidade dos testes rápidos}

Os TR foram avaliados seguindo rigorosamente o procedimento descrito nas instruções de uso de cada produto. Nos TR que incluíram a utilização de amostras de sangue total, um número mínimo de 25 amostras de sangue total positivas (spikes) e 25 de sangue total negativo foi avaliado. Para confecção dos spikes, amostras de sangue venoso coletadas com anticoagulante foram centrifugadas por $10 \mathrm{~min} / 4.200 \mathrm{~g}$, o plasma foi retirado e o concentrado de hemácias obtido diluído 1:2 em plasma/soro 
VP para os marcadores sorológicos da dengue avaliados (NS1, IgM e lgG). Um quantitativo aproximado de 50 testes por lote foi reservado para repetição em caso de resultados discordantes. Foram incluídas na avaliação da especificidade, duas amostras interferentes reagentes para cada um dos seguintes agentes etiológicos: $\mathrm{HIV}-1 / 2$, vírus da hepatite $\mathrm{C}(\mathrm{HCV})$, vírus da hepatite B (HBV) e HTLV-1/2.

Os resultados dos testes foram interpretados de acordo com as instruções dos fabricantes e os valores percentuais de sensibilidade e especificidade foram calculados ${ }^{45}$. 0 valor de sensibilidade de cada produto foi obtido com base no número de amostras VP analisadas e corretamente identificadas pelo teste avaliado, pela razão das VP somadas ao número de amostras FN. A especificidade foi determinada pelo número de amostras VN corretamente identificadas, pela razão das VN somadas ao quantitativo de amostras FP para a infecção pelo DENV. Os valores de sensibilidade e especificidade diagnóstica obtidos foram comparados com os declarados nas instruções de uso dos TR avaliados. Foram considerados satisfatórios, os TR que obtiveram valores de sensibilidade e especificidade iguais ou superiores aos declarados. Os TR com valores de sensibilidade e/ou especificidade inferiores aos declarados pelo fabricante foram considerados insatisfatórios. Após conclusão das análises, como parte do processo de registro de produto, os laudos de análise foram encaminhados à Anvisa, responsável pela conclusão dos processos e concessão dos registros.

Este estudo foi autorizado pelo Comitê de Ética em Pesquisa com Seres Humanos (CEP) do Instituto Oswaldo Cruz (IOC)/Fiocruz (CAAE: 55365316.7.0000.5248) sob o parecer $n^{\circ} 1590251$.

\section{RESULTADOS}

Do total de 32 TR encaminhados para análise prévia no INCQS, $31,3 \%(10 / 32)$ foi recebido em 2016, 53,1\% (17/32) em 2017 e $15,6 \%(5 / 32)$ em 2018 . Quanto à procedência dos produtos recebidos, 65,6\% (21/32) eram nacionais e $34,4 \%$ (11/32) importados da Ásia e Europa.

Um total de 40,6\% (13/32) correspondeu aos TR para detecção de Ag NS1, sendo 53,8\% (7/13) de procedência nacional e 46,2\% (6/13), importados. Dos 13 testes $(40,6 \%)$ para detecção de Ac $\operatorname{lgG} / \operatorname{lgM}, 84,6 \%$ (11/13) eram de fabricação nacional e 15,4\% (2/13), importados. Os testes para detecção de Ag/Ac NS1/ IgG/IgM corresponderam a 18,8\% (6/32) dos produtos avaliados, sendo $50,0 \%$ fabricados no país e $50,0 \%$ de origem importada.

Após avaliação dos parâmetros de sensibilidade e especificidade frente a amostras VP e VN, 71,9\% (23/32) dos produtos foram considerados satisfatórios e 28,1\% (9/32) insatisfatórios para um ou ambos parâmetros de desempenho. Dos TR satisfatórios, $65,2 \%(15 / 23)$ eram de procedência nacional e 34,8\% (8/23) importados. Dos testes considerados insatisfatórios, 66,7\% (6/9) eram nacionais e 33,3\% (3/9) importados. Dos 23 produtos satisfatórios, 39,1\% (9/23) corresponderam a TR para detecção do Ag NS1, cuja maioria, 62,5\% (5/8) era de produtos importados. Um total de $47,8 \%(11 / 23)$ correspondeu aos testes para detecção de Ac IgG/IgM, destes 66,7\% (10/15) eram nacionais e 12,5\% (1/8) importados. Testes para detecção de Ag/Ac (NS1/lgG/lgM) corresponderam a $13,1 \%(3 / 23)$ dos produtos analisados dos quais, $6,7 \%(1 / 15)$ eram nacionais e $25,0 \%(2 / 8)$, importados.

Nos TR para detecção de Ag NS1 satisfatórios, os valores de sensibilidade variaram de $88,3 \%$ a $100,0 \%$, sendo superiores aos $82,0 \%$ a $99,1 \%$ declarados pelos fabricantes. Os TR para detecção de Ac IgG/lgM mostraram valores de sensibilidade para Ac IgG que variaram de $97,5 \%$ a $100,0 \%$, iguais ou superiores aos $88,0 \%$ a $99,1 \%$ declarados. Para a detecção de Ac IgM, a sensibilidade variou de $99,0 \%$ a $100,0 \%$, obtendo-se valores iguais ou superiores aos $88,0 \%$ a $100,0 \%$ declarados pelos fabricantes (Tabela 1).

Nos TR para detecção de Ag/Ac combinados (NS1//gG/lgM), os valores de sensibilidade para NS1 foram de $85,7 \%$ a $100,0 \%$,

Tabela 1. Valores de sensibilidade e especificidade (\%) obtidos através da análise prévia e os valores declarados pelos fabricantes para os testes rápidos satisfatórios para detecção de Ag (NS1), Ac (IgG/lgM) e Ag/Ac NS1/lgG/lgM da dengue.

\begin{tabular}{|c|c|c|c|c|c|}
\hline \multirow{3}{*}{ Testes Rápidos } & \multirow{3}{*}{ Marcadores } & \multicolumn{4}{|c|}{ Satisfatórios $(n=23)$} \\
\hline & & \multicolumn{2}{|c|}{ Sensibilidade } & \multicolumn{2}{|c|}{ Especificidade } \\
\hline & & Obtida & Declarada & Obtida & Declarada \\
\hline \multicolumn{6}{|l|}{ Ag NS1 } \\
\hline $9 / 23$ & NS1 & $88,3 \%-100,0 \%$ & $82,0 \%-99,1 \%$ & $99,0 \%-100,0 \%$ & $95,0 \%-100,0 \%$ \\
\hline \multicolumn{6}{|l|}{$(39,1 \%)$} \\
\hline$A c \lg G / \lg M$ & $\lg G$ & $97,5 \%-100,0 \%$ & $88,0 \%-99,1 \%$ & $96,7 \%-100,0 \%$ & $96,2 \%-100,0 \%$ \\
\hline $11 / 23$ & $\lg M$ & $99,0 \%-100,0 \%$ & $88,0 \%-100,0 \%$ & $98,1 \%-100,0 \%$ & $96,2 \%-100,0 \%$ \\
\hline \multicolumn{6}{|l|}{$(47,8 \%)$} \\
\hline $\mathrm{Ag} / \mathrm{Ac} N \mathrm{NS} 1 / \lg \mathrm{g} / \lg M$ & NS1 & $85,7 \%-100,0 \%$ & $82,0 \%-99,1 \%$ & $98,5 \%-100,0 \%$ & $81,0 \%-100,0 \%$ \\
\hline $3 / 23$ & $\lg G$ & $100,0 \%$ & $88,0 \%-99,1 \%$ & $97,1 \%-99,3 \%$ & $96,2 \%-100,0 \%$ \\
\hline$(13,1 \%)$ & $\lg M$ & $100,0 \%$ & $88,0 \%-99,1 \%$ & $98,6 \%-100,0 \%$ & $98,6 \%-100,0 \%$ \\
\hline
\end{tabular}

Fonte: Laboratório de Sangue e Hemoderivados, 2019.

Ag: antígeno; Ac: anticorpos; IgG: imunoglobulina G; IgM: imunoglobulina $M$. 
e de $100,0 \%$ para Ac IgG e IgM, sendo superiores ou iguais aos valores esperados de $82,0 \%$ a $99,1 \%$ para NS1 e de $88,0 \%$ a $99,1 \%$ para lgG/lgM considerados portanto, satisfatórios (Tabela 1).

Os valores de especificidade apresentados nos TR satisfatórios para detecção de Ag NS1 variaram de $99,0 \%$ a 100,0\% e foram superiores ou iguais aos declarados pelos fabricantes. Nos TR para detecção de Ac IgG/lgM, a especificidade para Ac lgG foi de $96,7 \%$ a $100,0 \%$, sendo igual ou superior aos $96,2 \%$ a $100,0 \%$ declarados. Para a detecção de Ac lgM, a sensibilidade variou de $98,1 \%$ a $100,0 \%$, valor superior ou igual aos $96,2 \%-100,0 \%$ declarados pelos fabricantes. Nos testes combinados AgNS1/AclgG/ IgM, os valores de sensibilidade obtidos para NS1 foram de $98,5 \%$ a $100,0 \%$, superiores aos declarados de $81,0 \%$ a $100,0 \%$. A especificidade alcançada para Ac IgG foi de $97,1 \%$ a $99,3 \%$ e a declarada, de $96,2 \%$ a $100,0 \%$. A especificidade obtida para Ac IgM variou de $98,6 \%$ a $100,0 \%$ (Tabela 1 ).

Do total de nove TR insatisfatórios, 44,0\% (4/9) corresponderam aos TR para detecção de NS1, cuja sensibilidade obtida variou de $62,9 \%$ a $82,0 \%$ frente aos $88,3 \%-99,5 \%$ declarados pelos fabricantes e a especificidade de $97,8 \%-100,0 \%$ frente aos valores de $98,3 \%$ a $>99,9 \%$ declarados (Tabela 2 ).

Os TR insatisfatórios para detecção de Ac IgG/IgM corresponderam a $22,2 \%(2 / 9)$, sendo $50,0 \%(1 / 2)$ insatisfatório para sensibilidade para Ac IgM e 50,0\% (1/2), para sensibilidade e especificidade para Ac IgM e IgG (Tabela 2).

Os TR para detecção de Ag/Ac NS1/lgG/lgM representaram 33,3\% (3/9) dos resultados insatisfatórios, sendo 66,7\% (2/3) insatisfatórios em sensibilidade para Ag NS1 e 33,3\% (1/3) insatisfatórios em sensibilidade e especificidade para NS1/lgM/lgG (Tabela 2).

Do total de 33,3\% (3/9) que correspondiam aos TR insatisfatórios para detecção do Ag NS1 e Ac lgG/lgM, a sensibilidade para Ag NS1 variou de $80,6 \%$ a $99,0 \%$, sendo inferior à declarada pelos fabricantes de $90,8 \%$ a $100,0 \%$. A sensibilidade para Ac lgG e IgM foi de
$99,0 \%$ a $100,0 \%$ e a declarada, de $99,5 \%$ a $100,0 \%$. Os valores de especificidade para os TR empregados na pesquisa de Ag e Ac NS1/ $\operatorname{lgG} / \lg M$ da dengue foram inferiores aos declarados (Tabela 2).

Os produtos que apresentaram resultados de sensibilidade e/ou especificidade clínica insatisfatórios nas análises realizadas pelo INCQS, de acordo com as normas vigentes, não obtiveram registro do produto junto à Anvisa e, consequentemente, não foram comercializados no país.

\section{DISCUSSÃO}

O diagnóstico precoce dos casos de dengue é de vital importância no tratamento e na implementação de ações de saúde pública efetivas no combate à doença. 0 aumento do número de casos no mundo estimulou o interesse do setor privado no desenvolvimento e lançamento de novos produtos no mercado nacional e internacional. São características ideais de um teste diagnóstico, definido pelos critérios Assurance, nas quais se incluem os TR imunocromatográficos: a acessibilidade, a produção de poucos resultados FN (sensibilidade) e resultados FP (especificidade), a simplicidade na execução e o requerimento de treinamento mínimo, não necessitando de refrigeração para o armazenamento e de equipamentos para execução, além de fácil distribuição a aqueles que necessitam de diagnóstico em áreas de acesso restrito ${ }^{46}$.

Dentre os métodos disponíveis para o diagnóstico da dengue, os TR são amplamente utilizados tanto para detecção de Ag NS1 quanto para a detecção de Ac IgM e lgG individualmente ou combinados (NS1/lgG/lgM). São testes de execução simples, não necessitam de equipamento e podem ser realizados em tempo máximo de $20 \mathrm{~min}$. Por sua aplicabilidade e abrangência, os TR foram objeto de estudo, embora todas as metodologias empregadas no diagnóstico da dengue no país sejam rotineiramente avaliadas pelo INCQS. A análise prévia dos kits de diagnóstico da dengue constitui uma etapa

Tabela 2. Valores de sensibilidade e especificidade (\%) obtidos através da análise prévia e os valores declarados pelos fabricantes para os testes rápidos insatisfatórios para detecção de Ag (NS1), Ac (IgG/lgM) e Ag/Ac NS1/lgG/lgM da dengue.

\begin{tabular}{|c|c|c|c|c|c|}
\hline \multirow{3}{*}{ Testes Rápidos } & \multirow{3}{*}{ Marcadores } & \multicolumn{4}{|c|}{ Insatisfatórios $(\mathrm{n}=9)$} \\
\hline & & \multicolumn{2}{|c|}{ Sensibilidade } & \multicolumn{2}{|c|}{ Especificidade } \\
\hline & & Obtida & Declarada & Obtida & Declarada \\
\hline \multicolumn{6}{|l|}{ Ag NS1 } \\
\hline $4 / 9$ & NS1 & $62,9 \%-82,0 \%$ & $88,3 \%-99,5 \%$ & $97,8 \%-100,0 \%$ & $98,3->99,9 \%$ \\
\hline \multicolumn{6}{|l|}{$(44,0 \%)$} \\
\hline$A c \lg G / \lg M$ & $\lg G$ & $100,0 \%$ & $98,6 \%-100,0 \%$ & $80,4 \%-88,5 \%$ & $97,76 \%-99,0 \%$ \\
\hline $2 / 9$ & $\lg M$ & $88,4 \%-94,1 \%$ & $97,4 \%-97,9 \%$ & $80,4 \%-96,8 \%$ & $98,29 \%-99,0 \%$ \\
\hline \multicolumn{6}{|l|}{$(22,2 \%)$} \\
\hline $\mathrm{Ag} / \mathrm{Ac} N \mathrm{NS} 1 / \lg \mathrm{g} / \lg M$ & NS1 & $80,6 \%-99,0 \%$ & $90,8 \%-100,0 \%$ & $91,5 \%-98,7 \%$ & $92,1 \%-100,0 \%$ \\
\hline $3 / 9$ & $\lg G$ & $99,0 \%-100,0 \%$ & $99,5 \%-100,0 \%$ & $91,5 \%-98,7 \%$ & $98,5 \%-100,0 \%$ \\
\hline$(33,3 \%)$ & $\lg M$ & $99,0 \%-100,0 \%$ & $99,5 \%-100,0 \%$ & $91,5 \%-98,7 \%$ & $98,5 \%-100,0 \%$ \\
\hline
\end{tabular}

Fonte: Laboratório de Sangue e Hemoderivados, 2019.

Ag: antígeno; Ac: anticorpos; IgG: imunoglobulina G; IgM: imunoglobulina $M$. 
importante no processo de registro e, consequentemente, na disponibilização no mercado nacional de produtos sensíveis e específicos. Como verificado em avaliações de desempenho realizadas por organizações internacionais independentes, como a OMS, na tentativa de determinar os melhores testes diagnósticos comercialmente disponíveis, tem sido constatado o baixo desempenho desses produtos ${ }^{46,47,48}$. Os estudos realizados demonstraram valores de sensibilidade e especificidade abaixo dos declarados pelos produtores nas instruções de uso, desafiando os fabricantes na busca de melhoria no desempenho destes produtos ${ }^{23}$.

Segundo Blacksell ${ }^{49}$, até que as avaliações em grande escala sejam realizadas, muitos produtos de diferentes continentes são comercializados no mundo com pouca ou nenhuma verificação independentemente do desempenho. A qualidade das validações muitas vezes é questionada pela realização incorreta com ocorrência de falhas relacionadas ao quantitativo de amostras avaliadas, inconsistências nas metodologias, erros de interpretação, falhas na execução dos ensaios ou ainda o título de Ac empregados ${ }^{23,50}$. Cabe ressaltar que os valores de sensibilidade e especificidade declarados pelos fabricantes, nas instruções de uso até o presente, nortearam o mercado nacional e internacional para a aquisição e a utilização destes produtos, o que reforça a necessidade de avaliação constante.

Objetivando controlar a qualidade dos produtos oferecidos no mercado nacional, foram avaliados os parâmetros de sensibilidade diagnóstica de TR para detecção de Ag NS1, Ac IgG/lgM e AgNS1/AclgG/lgM, frente a painéis sorológicos de amostras clínicas coletadas no período de epidemia da doença (2010 a 2013) no Rio de Janeiro. A especificidade foi verificada frente a amostras de soro/plasma não reagentes caracterizadas como VN e a painéis comerciais, padrão de referência da OMS para dengue e amostras interferentes.

Em cumprimento à exigência de análise prévia emitida pela Anvisa desde a sua implementação, 32 diferentes TR foram analisados no período avaliado, sendo o maior quantitativo recebido em 2017, ano subsequente à implementação da análise prévia realizada em maio de 2016. 0 quantitativo de TR disponibilizados no mercado nacional é reflexo dos surtos da doença ocorridos nas últimas décadas e nas quatro grandes epidemias ocorridas no Brasil, associadas à alternância do sorotipo viral predominante: DENV-1, DENV-3, DENV-2, e DENV-4, atingindo um número total acumulado de 12.171 .009 casos prováveis da doença nos anos de 1998, 2002, 2008 e 2010, 2013, 2014, 201744.

O maior percentual de TR considerados insatisfatórios correspondeu aos produtos nacionais destinados à detecção do Ag NS1. No que diz respeito à procedência, se uma ou mais etapas críticas do processo de fabricação do produto forem realizadas no Brasil, o produto é registrado como nacional, conforme legislação vigente, ainda que sejam utilizados na fabricação Ag e/ou Ac e componentes importados ${ }^{50}$.

A proteína NS1, identificada como um marcador precoce da dengue aguda, está presente entre o primeiro e o nono dia após o início da doença, entretanto, após a soroconversão, pode ser difícil detectá-la no soro. Diferentes grupos em vários países relataram baixa sensibilidade nos ensaios NS1 em comparação com os métodos moleculares, principalmente em populações que sofreram surtos sequenciais desta doença. Como esse achado é definitivamente mais pronunciado em infecções secundárias, já foi sugerido que o Ag NS1 poderia ser sequestrado em imunocomplexos com lgG. Em estudo realizado na população brasileira, pelo menos $68 \%$ dos pacientes tinham infecção secundária por dengue, o que poderia explicar um menor desempenho (menos de $40 \%$ de positividade) do teste $26,28,51,52$.

O desempenho dos TR para detecção do Ag NS1, isoladamente ou combinado com a detecção de Ac IgM ou IgG, tem sido avaliado $^{26,28}$. Embora os resultados nem sempre sejam consistentes entre diferentes coortes e testes, vários comentários gerais podem ser feitos. A sensibilidade é mais alta nas infecções primárias, quando o teste ocorre logo após o início dos sintomas e quando a IgG não é detectável. Variações na sensibilidade dependem do sorotipo das amostras avaliadas e da sensibilização por Ac ou Ag empregados nas tiras do teste utilizado.

Os TR para detecção de Ac IgG/lgM apresentaram o melhor desempenho de sensibilidade dentre os produtos avaliados. Testes para detecção de Ac IgM e lgG são rotineiramente utilizados em laboratórios clínicos e podem diferenciar entre infecções primárias e secundárias. $\mathrm{O}$ uso combinado de IgM e IgG mostrou aumentar a sensibilidade na detecção da infecção pelo DENV. Segundo a Organização Pan-Americana de Saúde (OPAS), $80 \%$ de todos os casos de dengue têm Ac IgM detectáveis no quinto dia e em $93 \%$ a $99 \%$ dos casos entre o sexto e o décimo dias. Os níveis de $\lg M$ aumentam rapidamente e atingem seu pico por volta de duas semanas, permanecendo detectáveis por dois a três meses, o que faz desses Ac indicadores de infecções recentes ${ }^{27,49}$. Os Ac IgG começam a ser detectados na resposta primária, alguns dias após os Ac IgM, sendo detectáveis a partir do quinto dia de doença e permanecendo por toda a vida. A resposta secundária é caracterizada pelo rápido aumento de IgG quase que imediatamente após o início dos sintomas ${ }^{31}$. Os níveis de IgM na resposta secundária são consideravelmente mais baixos do que na resposta primária. Sabe-se que os valores divergentes de sensibilidade e especificidade obtidos podem estar associados às diferentes populações analisadas, ao quantitativo de amostras, estágio da infecção ou ainda nas infecções prévias por diferentes sorotipos ${ }^{53}$.

Nas Américas, a existência de transmissão local de múltiplas arboviroses e a reatividade cruzada entre flavoviroses, em particular a dengue e a zika, são conhecidas, sendo um desafio a identificação dos agentes infectantes. Embora a reatividade cruzada entre os Flavivírus seja descrita, não foram incluídas na avaliação amostras reagentes para zika (IgM ou IgG), pois, no período de análise proposto (2016-2018), ainda não se encontravam comercialmente disponíveis painéis sorológicos de desempenho ou padrões internacionais para zika, sendo, portanto, uma limitação do estudo ${ }^{19}$. 
Atualmente, os TR usados no Brasil para o diagnóstico da dengue são empregados em ambientes de atenção primária e laboratórios clínicos. A utilização de testes com desempenho inferior ao esperado ou mesmo sem validação adequada desafia o sistema de saúde. A utilização de TR com desempenho insatisfatório para a detecção e gestão de casos de dengue pode levar ao aumento de resultados FN ou FP e consequente aumento dos casos letais da doença por tratamento inadequado ou ausência de tratamento ${ }^{54}$. Desta forma, alertamos que a avaliação frequente desses produtos se faz necessária, não só no momento do registro (análise prévia) mas através da realização de análise controle (pós-comercialização).

A avaliação da estabilidade dos produtos mediante as condições de estocagem e transporte, embora não tenha sido objeto deste trabalho, deve ser levada em consideração, pois o Brasil é um país de dimensões continentais com temperaturas e umidades relativas variadas. Em estudo realizado por Sengvilaipaseuth et al. ${ }^{55}$, foi verificado que componentes (Ac) de um TR foram afetados pela estocagem em temperatura elevada, reduzindo a sensibilidade do produto.

\section{CONCLUSÕES}

Por sua aplicabilidade e abrangência, os TR são ferramentas amplamente utilizadas no diagnóstico da dengue tanto para detecção de Ag NS1, quanto para a detecção de Ac IgM e lgG. $\mathrm{Na}$ aquisição de tais produtos, parâmetros de sensibilidade e especificidade declarados nas instruções de uso norteiam o mercado nacional e internacional. Objetivando controlar a qualidade dos produtos oferecidos no mercado nacional foram avaliados os parâmetros de sensibilidade e especificidade clínica ou diagnóstica dos TR imunocromatográficos empregados no diagnóstico sorológico da dengue, como parte do processo de obtenção do registro junto à Anvisa. Os resultados obtidos foram comparados aos valores declarados nas instruções de uso dos produtos para esses atributos. Dos 32 TR encaminhados para análise, 23 apresentaram resultados satisfatórios para os parâmetros de sensibilidade e especificidade. Os TR para detecção de Ac IgG/IgM apresentaram o melhor desempenho de sensibilidade dentre os produtos avaliados. Um total de nove TR foi considerado insatisfatório e correspondeu aos produtos destinados à detecção do Ag NS1. Os testes insatisfatórios não obtiveram registro e, consequentemente, não foram comercializados no país.

A avaliação laboratorial prévia ao registro do produto possibilita a disponibilização no mercado nacional de TR sensíveis e específicos, ampliando a qualidade, a segurança e a confiabilidade dos produtos destinados ao diagnóstico da dengue comercializados no Brasil.

\section{REFERÊNCIAS}

1. Murray NEA, Quam MB, Wilder-Smith A. Epidemiology of dengue: past, present and future prospects. Clin Epidemiol. 2013;5:299-309. https://doi.org/10.2147/CLEP.S34440

2. Katzelnik LC, Coloma J, Harris E. Dengue: knowledge gaps, unmet needs, and research priorities. Lancet Infect Dis. 2017;17(3):e88-e100. https: //doi.org/10.1016/S1473-3099(16)30473-X

3. Gubler DJ. Dengue, urbanization and globalization: the unholy trinity of the 21st Century. Trop Med Health. 2011;39(4 Supl):3-11. https://doi.org/10.2149/tmh.2011-S05

4. Ministério da Saúde (BR). Monitoramento dos casos de arboviroses urbanas transmitidas pelo Aedes aegypti (dengue, chikungunya e zika), semanas epidemiológicas 1 a 26, 2020. Boletim Epidemiológico 28. 14 jul 2020[acesso 3 ago 2020]. Disponível em: https://www.saude.gov.br/images/pdf/2020/ July/14/Boletim-epidemiologico-SVS-28-v2.pdf

5. Kraemer MU, Sinka ME, Duda KA, Mylne AQ, Shearer FM, Barker $C M$ et al. The global distribution of the arbovirus vectors Aedes aegypti and Aedes albopictus. Elife. 2015;4:1-18. http://doi.org/10.7554/eLife.08347

6. Fares RCG, Souza KPR, Añez G, Rios M. Epidemiological scenario of dengue in Brazil. Biomed Res Int. 2015;1-13. https://doi.org/10.1155/2015/321873

7. Wiwanitkit V. Non vector-borne transmission modes of dengue. J Infect Dev Countries. 2010;4(1):51-4.

8. Barthel A, Gourinat AC, Cazorla C, Joubert C, DupontRouzeyrol M, Descloux E. Breast milk as a possible route of vertical transmission of dengue virus? Clin Infec Dis. 2013;57(3):415-7. https://doi.org/10.1093/cid/cit227

9. Lopes N, Nozawa C, Linhares REC. Características gerais e epidemiologia dos arbovírus emergentes no Brasil. Rev Pan-Amaz Saude. 2014;5(3):55-64. https://doi.org/10.5123/S2176-6223201400030000

10. Gibbons RV, Kalanarooj S, Jarman RG, Nisalak A, Vaughn DW, Endy TP et al. Analysis of repeat hospital admissions for dengue to estimate the frequency of third or fourth dengue infections resulting in admissions and dengue hemorrhagic fever, and serotype sequences. Am J Trop Med Hyg. 2007;77(5):910-3.

11. Martinez TE. Dengue. Estud Av. 2008;22(64):33-52.

12. World Health Organization - WHO. Dengue vaccine: WHO position paper: July 2016. Weekly Epidemiological Record. 29 jul 2020[acesso 1 mar 2018]. Disponível em: http:/ / www. who.int/wer/2016/wer9130.pdf?ua=1

13. Kaptein SJF, Neyts J. Towards antiviral therapies for treating dengue virus infections. Curr Opin Pharmacol. 2016;30:1-7. https://doi.org/10.1016/j.coph.2016.06.002

14. Ooi EE, Goh KT, Gubler DJ. Dengue prevention and 35 years of vector control in Singapore. Emerg Infect Dis. 2006;12(6):887-93. https://doi.org/10.3201/10.3201/eid1206.051210

15. Bhatt S, Gething PW, Brady OJ, Messina JP, Farlow AW, Moyes $\mathrm{CL}$ et al. The global distribution and burden of dengue. Nature. 2013;496(7446):504-7. https://doi.org/10.1038/nature12060 
16. Chatchen S, Sabchareon A, Sirivichayakul C. Serodiagnosis of asymptomatic dengue infection. Asian Pac J Trop Med. 2017;10(1):111-4. https://doi.org/10.1016/j.apjtm.2016.12.002

17. Oliveira MJC, Cordeiro MT, Costa FM, Murakami G, Silva AMS, Travassos RC et al. Frequência de sarampo, rubéola, dengue e eritema infeccioso entre casos suspeitos de sarampo e rubéola no estado de Pernambuco, no período de 2001-2004. Rev Soc Bras Med Trop. 2008;41(4):338-44. https://doi.org/10.1590/\$0037-86822008000400004

18. Dircio MSA, González FE, María SVG, Elizabeth SH, Beatriz RS, Altuzar AVM et al. Leptospirosis prevalence in patients with initial diagnosis of dengue. J Trop Med. 2012;(2012):15. https://doi.org/10.1155/2012/519701

19. Felix AC, Souza NCS, Figueiredo WM, Costa AA, Inenami M, Silva RMG. Cross reactivity of commercial anti-dengue immunoassays in patients with acute zika virus infection. J Med Virol. 2017;89(8):1477-9. https://doi.org/10.1002/jmv.24789

20. Moreli ML, Costa VG. A systematic review of molecular diagnostic methods for the detection of arboviruses in clinical specimens in Brazil and the importance of a differential diagnosis. Virol Discov. 2013; $1: 1$. https://doi.org/10.7243/2052-6202-1-1

21. Mota MTO, Terzian AC, Silva MLCR, Estofolete C, Nogueira ML. Mosquito-transmitted viruses: the great brazilian challenge. Braz J Microbiol. 2016;47(Supl 1):38-50. https://doi.org/10.1016/j.bjm.2016.10.008

22. Mungrue $K$. The laboratory diagnosis of dengue virus infection, a review. Adv Lab Med Int. 2014;4(1):1-8.

23. Peeling RW, Smith PG, Bossuyt PMM. A guide for diagnostic evaluations. Nat Rev Microbiol. 2006;4(12 Supl):S2-S6. https: / /doi.org/10.1038/nrmicro1568

24. Alcon S, Talarmin A, Debruyne M, Falconar A, Deubel V, Flamand $M$. Enzyme-linked immunosorbent assay specific to dengue virus type 1 nonstructural protein NS1 reveals circulation of the antigen in the blood during the acute phase of disease in patients experiencing primary or secondary infections. J Clin Microbiol. 2002;40(2):376-81. https://doi.org/10.1128/jcm.40.02.376-381.2002

25. Kassim FM, Izati MN, TgRogayah TA, Apandi YM, Saat Z. Use of dengue NS1 antigen for early diagnosis of dengue virus infection. Southeast Asian J Trop Med Public Health. 2011;42(3):562-9.

26. Zhang H, Li W, Wang J, Peng H, Che X, Chen X et al. NS1based tests with diagnostic utility for confirming dengue infection: a meta-analysis. Int J Infect Dis. 2014;(26):57-66. https://doi.org/10.1016/j.ijid.2014.02.002

27. Nogueira RM, Miagostovich MP, Cavalcanti SMB, Marzochi KBF, Schatzmayr HG. Levels of IgM antibodies against dengue virus in Rio de Janeiro, Brazil. Res Virol. 1992;143(6):423-7. https://doi.org/10.1016/s0923-2516(06)80136-6

28. Andries AC, Duong V, Ong S, Ros S, Sakuntabhai A, Horwood $\mathrm{P}$ et al. Evaluation of the performances of six commercial kits designed for dengue NS1 and anti-dengue $\lg \mathrm{M}$, IgG and IgA detection in urine and saliva clinical specimens. BMC Infect Dis. 2016;16:1-9. https://doi.org/10.1186/s12879-016-1551-x
29. Balmaseda A, Guzmán MG, Hammond S, Robleto G, Flores $C$, Téllez $Y$ et al. Diagnosis of dengue virus infection by detection of specific immunoglobulin $M(\lg M)$ and $\lg A$ antibodies in serum and saliva. Clin Diagn Lab Immunol. 2003;10(2):317-22. https://doi.org/10.1128/cdli.10.2.317-322.2003

30. Muller DA, Depelsenaire ACI, Young PR. Clinical and laboratory diagnosis of dengue virus infection. J Infect Dis. 2017;215(Supl 2):S89-\$95. https://doi.org/10.1093/infdis/jiw649

31. Zhang B, Salieb-Beugelaar GB, Nigo MM, Weidmann M, Hunziker P. Diagnosing dengue virus infection: rapid tests and the role of micro/ nanotechnologies. Nanomedicine. 2015;11(7):1745-61. https://doi.org/10.1016/j.nano.2015.05.009

32. Felix AC, Romano CM, Centrone CC, Rodrigues CL, VillasBoas L, Araújo ES et al. Low sensitivity of NS1 protein tests evidenced during a dengue type 2 virus outbreak in Santos, Brazil, in 2010. Clin Vac Immunol. 2012;19(12):1972-6. https://doi.org/10.1128/CVI.00535-12

33. Sea VRF, Cruz ACR, Gurgel RQ, Nunes BTD, Silva EVP, Dolabella SS et al. Underreporting of dengue 4 in Brazil due to low sensitivity of the NS1 Ag test in routine control programs. PLoS One. 2013;8(5):1-3. https://doi.org/10.1371/journal.pone.0064056

34. Hunsperger EA, Yoksan S, Buchy P, Nguyen VC, Sekaran SD, Enria DA et al. Evaluation of commercially available diagnostic tests for the detection of dengue virus NS1 antigen and anti-dengue virus IgM antibody. PLoS Negl Trop Dis. 2014;8(10):1-11. https://doi.org/10.1371/journal.pntd.0003171

35. Pal S, Dauner AL, Mitra I, Forshey BM, Garcia P, Morrison $A C$ et al. Evaluation of dengue NS1 antigen rapid tests and Elisa kits using clinical samples. PLoS One. 2014;9(11):1-8. https://doi.org/10.1371/journal.pone.0113411

36. Peeling RW, Artsob H, Pelegrino JL, Buchy P, Cardosa MJ, Devi $S$ et al. Evaluation of diagnostic tests: dengue. Nature Rev Microbiol. 2010;8(12 Supl):S30-8. https://doi.org/10.1038/nrmicro2459

37. Blacksell SD, Bell D, Kelley J, Mammen Jr MP, Gibbons RV, Jarman RG et al. Prospective study to determine accuracy of rapid serological assays for diagnosis of acute dengue virus infection in Laos. Clin Vac Immunol. 2007;14(11):145864. https://doi.org/10.1128/CVI.00482-06

38. Lima, MRQ. Antígeno NS1 dos vírus dengue: desempenho de testes disponíveis comercialmente e aplicações alternativas para o diagnóstico precoce das infecções por dengue [dissertação]. Rio de Janeiro: Fundação Oswaldo Cruz; 2014.

39. Brasil. Lei $\mathrm{N}^{\circ} 5.991$, de 17 de dezembro de 1973. Dispõe sobre o controle sanitário do comércio de drogas, medicamentos, insumos farmacêuticos e correlatos, e dá outras providências. Diário Oficial União. 18 dez 1973.

40. Brasil. Decreto № 74.170, de 10 de junho de 1974. Regulamenta a lei № 5.991, de 17 de dezembro de 1973, que dispõe sobre o controle sanitário do comércio de drogas, medicamentos, insumos farmacêuticos e correlatos. Diário Oficial União. 11 jun 1973. 
41. Agência Nacional de Vigilância Sanitária - Anvisa. Resolução RDC No 36, de 26 de agosto de 2015. Dispõe sobre a classificação de risco, os regimes de controle de cadastro e registro eos requisitos de rotulagem e instruções de uso de produtos para diagnóstico in vitro, inclusive seus instrumentos e dá outras providências. Diário Oficial União. 27 ago 2015.

42. Agência Nacional de Vigilância Sanitária - Anvisa. Resolução RDC N ${ }^{\circ} 270$, de 28 de fevereiro de 2019. Dispõe sobre a migração do regime de cadastro para o regime de notificação dos dispositivos médicos de classe de risco I. Diário Oficial União. 1 mar 2019.

43. Brasil. Lei № 6.360 de 23 de setembro de 1976. Dispõe sobre a vigilância sanitária a que ficam sujeitos os medicamentos, as drogas, os insumos farmacêuticos e correlatos, cosméticos, saneantes e outros produtos, e dá outras providência. Diário Oficial União. 24 mar 1976.

44. Borges HCBG. Avaliação dos conjuntos diagnósticos (kits) empregados no diagnóstico da dengue no Brasil [tese]. Rio de Janeiro: Fundação Oswaldo Cruz; 2017.

45. Guimarães MCS. Exames de laboratório: sensibilidade, especificidade, valor preditivo positivo. Rev Soc Bras Med Trop. 1985;18(2):117-20. https://doi.org/10.1590/S0037-86821985000200009

46. Kosack CS, Page AL, Klatser PR. A guide to aid the selection of diagnostic tests. Bull World Health Organ. 2017;95(9):639-45. https://doi.org/10.2471/BLT.16.187468

47. Fry SR, Meyer M, Semple MG, Simmons CP, Sekaran $S D$, Huang JX et al. The diagnostic sensitivity of dengue rapid test assays is significantly enhanced by using a combined antigen and antibody testing approach. PLoS Negl Trop Dis. 2011;5(6):1-8. https://doi.org/10.1371/journal.pntd.0001199

48. Centers of Disease Control and Prevetion - CDC. Testing for dengue virus. Atlanta: Centers of Disease Control and Prevetion; 2017[acesso 2 fev 2017]. Disponível em: https: / /www.cdc.gov/dengue/clinicallab/laboratory.html
49. Blacksell SD. Commercial dengue rapid diagnostic tests for point-of-care application: recent evaluations and future needs? J Biomed Biotechnol. 2012; ID 151967. https://doi.org/10.1155/2012/151967

50. Agência Nacional de Vigilância Sanitária - Anvisa. Resolução RDC No 185 de 22 de outubro de 2001. Trata do registro, alteração, revalidação e cancelamento do registro de produtos médicos na Agência Nacional de Vigilância Sanitária. Diário Oficial União. 24 out 2001.

51. Guzman MG, Jaenisch T, Gaczkowski R, Hang VTT, Sekaran SD, Kroeger A et al. Multi-country evaluation of the sensitivity and specificity of two commercially-available NS1 Elisa assays for dengue diagnosis. PLoS Negl Trop Dis. 2010;4(8):1-10. https://doi.org/10.1371/journal.pntd.0000811

52. Lima MRQ, Nogueira RMR, Schatzmayr HG, Santos FB. Comparison of three commercially available dengue NS1 antigen capture assays for acute diagnosis of dengue in Brazil. PLoS Negl Trop Dis. 2010;4(7):1-8. https://doi.org/10.1371/journal.pntd.0000738

53. Innis BL, Nisalak A, Nimmannitya S, Kusalerdchariya $S$, Chongswasdi V, Suntayakorn $S$ et al. An enzymelinked immunosorbent assay to characterize dengue infections where dengue and japanese encephalitis co-circulate. Am J Trop Med Hyg. 1989;40(4):418-27. https://doi.org/10.4269/ajtmh.1989.40.418

54. Liu LT, Dalipanda T, Jagilly R, Wang YH, Lin PC, Tsai $\mathrm{CY}$ et al. Comparison of two rapid diagnostic tests during a large dengue virus serotype 3 outbreak in the Solomon Islands in 2013. PLoS One. 2018;13(8):1-12. https://doi.org/10.1371/journal.pone.0202304

55. Sengvilaipaseuth $O$, Phommasone $K$, Lamballerie $X$, Vongsouvath $M$, Phonemixay $O$, Blacksell SD et al. Temperature stability of a dengue rapid diagnostic test under tropical climatic conditions: a follow up study. PLoS One 2017;12(1):1-7. https://doi.org/10.1371/journal.pone. 0170359

\section{Agradecimentos}

O presente trabalho foi fomentado através do projeto denominado "Avaliação dos conjuntos diagnósticos empregados no diagnóstico sorológico da dengue no Brasil”, em parceria com a Anvisa e o Programa das Nações Unidas para o Desenvolvimento (PNUD), tendo sido aprovado por meio da Carta Acordo n 27429/2013, publicada em 7 de março de 2014, no Diário Oficial da União (D.0.U.) $n^{\circ}$ 45, seção 3 , às páginas 179 e 180, Processo $n^{\circ}$ 25351.602897/2013-13, e realizado com apoio da Coordenação de Aperfeiçoamento de Pessoal de Nível Superior - Brasil (CAPES) - Código de Financiamento 001.

\section{Contribuição dos Autores}

Borges HCBG - Concepção, planejamento (desenho do estudo), aquisição, análise, interpretação dos dados e redação do trabalho. Adati MC Concepção, planejamento (desenho do estudo), interpretação dos dados e redação do trabalho. Vigo DC, Mendonça VF, Issobe MA - Análise e interpretação dos resultados. Santos FB, Zamith HPS - Redação do trabalho. Todos os autores aprovaram a versão final do trabalho.

\section{Conflito de Interesse}

Os autores informam não haver qualquer potencial conflito de interesse com pares e instituições, políticos ou financeiros deste estudo.

Licença CC BY-NC atribuição não comercial. Com essa licença é permitido acessar, baixar (download), copiar, imprimir, compartilhar, reutilizar e distribuir os artigos, desde que para uso não comercial e com a citação da fonte, conferindo os devidos créditos de autoria e menção à Visa em Debate. Nesses casos, nenhuma permissão é necessária por parte dos autores ou dos editores. 